\title{
Fatigue in older adults: an early indicator of the aging process?*
}

\author{
Kirsten Avlund $1,2,3,4$ \\ ${ }^{1}$ Department of Social Medicine, Institute of Public Health, University of Copenhagen, ${ }^{2}$ Research Centre for \\ Prevention and Health, Copenhagen County, ${ }^{3}$ Danish Aging Research Centre, University of Aarhus, Odense and \\ Copenhagen, ${ }^{4}$ Center for Healthy Aging, University of Copenhagen, Denmark
}

ABSTRACT. The aim of this paper is to give an overview of research on fatigue in older adults, with a focus on fatigue as an early indicator of the aging process. Fatigue is a strong predictor of functional limitations, disability, mortality, and other adverse outcomes in young-old and old-old populations, between men and women, and in different geographic localities. Several biological, physiological and social explanations are proposed: fatigue may be seen not only as a self-reported indicator of frailty, defined as a physiologic state of increased vulnerability to stressors, which results from decreased physiologic reserves and even dysregulation of multiple physiologic systems, but also this state may be accelerated because of the cumulative impact of social, mental and biological factors throughout life.

(Aging Clin Exp Res 2010; 22: 100-115)

${ }^{\circ}$ 2010, Editrice Kurtis

\section{INTRODUCTION}

Fatigue is a common complaint among older adults and one of the most frequent reasons for encounter in general practice (1-4): it is often a symptom of underlying psychiatric or medical illness, such as cancer, heart disease, depression, chronic lung disease, hypothyroidism, multiple sclerosis, and rheumatoid arthritis (1, 5-7). Fatigue is also prevalent in certain medical treatments, such as radiation or chemotherapy. In many such cases fatigue is often one of the most important causes of disablement, frequently reported by patients with significant illness as one of their most severe symptoms (7). However, for many older persons, it is not possible to identify a phys- iological or psychological cause, and fatigue becomes a syndrome, which the older person must attempt to manage in all daily activities $(8,9)$. With no known specific biological marker or other possible causes, fatigue in older adults is a complaint which is not fully understood.

After World War I, an Industrial Fatigue Board was formed in England, partly to search for an objective test for fatigue. It reported in strong terms, demanding "that the term fatigue be absolutely banished from precise scientific discussion, and consequently that attempts to obtain a fatigue test be abandoned". Similar disillusionment was largely due to the realisation that fatigue is a subjective experience that cannot be measured by objective methods (10). Advancing knowledge has further been hindered by several barriers, such as lack of clarity about different aspects of fatigue, minimal standardization of its measurement, its strong subjective nature, and surprisingly few data on fatigue among older persons (5).

\section{PREVALENCE OF FATIGUE}

Fatigue is relatively prevalent in the general older population. A study of middle-aged and older community-dwelling Europeans living in 10 countries showed that its prevalence varied from $20 \%$ in Germany to $38 \%$ in Spain among 50-64-year olds, and from 28\% in Austria to $55 \%$ in Spain among persons 65 years or older (11). Data from the Glostrup Aging Studies showed that the proportion of men and women who felt fatigued in their daily activities increased with age from age 70 to age 85 (Table 1). About half of the study population felt fatigued when they were 70 years old, compared with more than

\footnotetext{
*Review article based on the $5^{\text {th }}$ Andrus Viidik Lecture in Gerontology, given by K. Avlund at the 20th Nordic Congress of Gerontology, Reykjavik, Iceland, May 30 - June 2, 2010. The Nordic Gerontological Federation (NGF) initiated these lectures when Professor Viidik retired from the NGF, after having been its Secretary (1974-1988) and Chairman (1988-2002).

Key words: Disability, fatigue, frailty, functional limitations.

Correspondence: Kirsten Avlund, DrMedSci, Department of Social Medicine, Institute of Public Health, Nørre Farimagsgade 5, P.O. 2099, 1014 Copenhagen K, Denmark.

E-mail: kiav@sund.ku.dk

Received November 20, 2009; accepted in revised form February 18, 2010.
} 
Table 1 - Proportion of 70-, 75-, 80-, and 85-year old men and women who felt fatigued in daily activities.

\begin{tabular}{lccc}
\hline Age & Men with fatigue & Women with fatigue & $\boldsymbol{p}$ \\
\hline 70 & $(\mathrm{n}=364) 51 \%$ & $(\mathrm{n}=367) 55 \%$ & 0.406 \\
75 & $(\mathrm{n}=337) 59 \%$ & $(\mathrm{n}=411) 68 \%$ & 0.005 \\
80 & $(\mathrm{n}=184) 58 \%$ & $(\mathrm{n}=248) 68 \%$ & 0.045 \\
85 & $(\mathrm{n}=77) 79 \%$ & $(\mathrm{n}=119) 87 \%$ & 0.126 \\
\hline
\end{tabular}

Fatigued: Measured by Mob-T Scale (See Table 3); $p$ : differences between men and women, by chi-square tests.

$75 \%$ of the 85 -year-olds. No gender differences were seen at age 70 but, as the population grew older, significantly more women felt fatigued in their daily activities compared with the men. Table 2 shows the individual changes in self-reported fatigue in daily activities in the different follow-up periods. In all three follow-up periods, a large proportion of old people had sustained fatigue. Until the age of 80 , a rather large proportion reported no fatigue in the follow-up periods, and some people also recovered from a period with fatigue. However, very few recovered from fatigue from age 80 to 85 , while a substantial proportion declined. More women than men had sustained fatigue in all follow-up periods.

Several other studies have reported higher prevalences of fatigue in women than in men $(4,12-16)$. A cross-sectional Danish population study in a random age-stratified sample of 16-77-year-old persons showed that, on average, there was not much difference in fatigue between men and women, but that there was an excess of women among persons with very high levels of fatigue (17). It is not known whether women experience more severe fatigue than men, or whether the findings merely reflect the greater willingness of women to report health problems.

Contradictory results are found in the relationship between age and fatigue. Some authors found no correlation $(18,19)$; one study $(20)$ found that the prevalence of both chronic and non-chronic fatigue decreases with age; others found a positive correlation $(1,12,21,22)$. The results from the Danish population study among a random sample of 16-77-year-olds (17) may explain the ambiguity in this research. Fatigue decreased with age in the healthy part of the population, but increased with age among those with a chronic disease.

\section{AIM}

The aim of this paper is to give an overview of research on fatigue in older adults, with a focus on fatigue as an early indicator of the aging process.

\section{DEFINITIONS OF FATIGUE}

Fatigue is an ambiguous concept, which especially relates to the reaction to physical and psychological work loads, but it may also include many different experiences and states of mind, e.g., the experience of exhaustion, impaired energy and vitality, and need for sleep. Further, fatigue is the normal physiological reaction in an organism, a part of the body, or an organ, which has reached the limits of its capacity after heavy strain. Fatigue is a general reaction to many biological processes after intensive and/or long-lasting work, because metabolic demands cannot be met. This may occur outside the central nervous system, e.g., in muscles, after heavy and intensive stimulation, as feedback from joints, muscles and tendons (23). Muscle fatigue has been defined as a fall in the maximum force-generating capacity of the muscle and its failure to maintain the required force, resulting from muscle activity, but reversible by rest. Muscle fatigue is considered to be both a "negative" consequence of physical activity and a "positive" safety mechanism, to prevent injury or death during exercise (23). Centrally conditioned fatigue is more complex, and entails both chemical and hormonal factors in nerve cells and their synapses, e.g., as changes in neurotransmitter levels in various brain structures (24), but also psychological factors such as endurance, motivation $(25,26)$, mood, and expectation of task difficulty $(23,27)$. Fatigue which cannot be relieved by rest or sleep is a frequent sign of disease. In its chronic form, it may be considered a disease in itself, or may be a personality trait throughout life $(25,26)$. Fatigue may be acute or chronic: acute fatigue has a rapid onset and a

Table 2 - Changes in fatigue in daily activities (measured by Mob-T Scale) among men and women from age 70 to 75,75 to 80 and 80 to 85.

\begin{tabular}{|c|c|c|c|c|c|c|c|c|c|}
\hline \multirow[t]{2}{*}{ State } & \multicolumn{3}{|c|}{ From age 70 to 75} & \multicolumn{3}{|c|}{ From age 75 to 80} & \multicolumn{3}{|c|}{ From age 80 to 85} \\
\hline & Men & Women & $p$ & Men & Women & $p$ & Men & Women & $p$ \\
\hline (n) & $(265)$ & (310) & & $(185)$ & $(248)$ & & $(75)$ & $(118)$ & \\
\hline Not fatigued - not fatigued & $33 \%$ & $25 \%$ & & $29 \%$ & $20 \%$ & & $19 \%$ & $8 \%$ & \\
\hline Not fatigued - fatigued & $23 \%$ & $21 \%$ & & $21 \%$ & $17 \%$ & & $35 \%$ & $33 \%$ & \\
\hline Fatigued - not fatigued & $8 \%$ & $7 \%$ & & $13 \%$ & $12 \%$ & & $0 \%$ & $4 \%$ & \\
\hline Fatigued - fatigued & $35 \%$ & $47 \%$ & 0.034 & $37 \%$ & $50 \%$ & 0.033 & $47 \%$ & $54 \%$ & 0.056 \\
\hline
\end{tabular}


short duration, and generally does not affect a person's quality of life. Chronic fatigue is usually generalized (involving physical and psychological symptoms), lasts longer, and a quick remission is not expected $(7,28)$.

Fatigue may be defined in many ways $(29,30)$. Feeling very tired is a human experience often referred to as fatigue, decreased vitality, loss of energy, anergia, exhaustion, tiredness, weakness and lassitude. Many authors use these words interchangeably, but some emphasize a difference in their meaning. For example, fatigue has a voluntary aspect, whereas weakness may not; tiredness has been defined as a universal sensation expected to occur normally at certain times of the day and with various kinds of activities. It is thought to be temporary and often considered a sensation that is relieved by rest and sleep (31). It has also been suggested that fatigue is part of a continuum, including tiredness, fatigue and exhaustion, representing increasing levels of illness or functional decline (29). In accordance with most authors I use here the term fatigue in spite of the distinctions made by others. This is in agreement with Ream and Richardson (32), who defined fatigue as: "A subjective unpleasant symptom which incorporates total body feeling ranging from tiredness to exhaustion, creating an unrelenting overall condition which interferes with individuals' ability to function to their normal capacity".

An additional problem arises when the concept fatigue is translated from English to other languages or vice versa. Lerdahl et al. (14) had several problems during translation of the US-English version of a fatigue measure into Norwegian. The conclusion was that the Norwegian word similar to tired implies a weaker state than does the English word, and that the Norwegian word closest to exhaustion seems to be stronger than fatigue. In the end, the Norwegian words which were back-translated as tired and weary were selected as the closest equivalent to fatigue. Similarly, Avlund et al. (e.g. 33, 34) have consequently translated the Danish term for "tiredness" to "tiredness" in English, until very recently, although the concept in Danish may be closer to fatigue used in English, depending on definition. As a consequence, this terminology has been changed in the most recent publications from this group.

\section{The feeling of fatigue}

With the aim of studying the broad question of what fatigue is in a healthy population, Aaronson et al. (5) made a qualitative study with in-depth interviews among the employees, aged 30-60 years, of a large Midwestern United States medical center working in all job categories. They found that fatigue was manifested or experienced in four themes: 1) in objective physical manifestations, which can be observed by others and include slumped posture, bloodshot eyes, drawn face, and wrinkled forehead or brow; 2) in subjective physical manifestations, which are not necessarily visible to others and which include weakness, decreased energy, lack of endurance, sleepiness, physical exhaustion, dizziness, headaches, and heaviness head to toe; 3) in emotional/mental manifestations, which include weariness, lack of enthusiasm, intolerance, moodiness, forgetfulness, lacking desire or will to do anything, feeling overextended, unorganized, frustrated, confused, or grouchy; 4) in behavioral manifestations, which include being short-tempered, not getting things done, making mistakes, being unproductive, and generally not functioning in one's usual manner. The participants made a clear distinction between acute and chronic fatigue, which paralleled the distinction between fatigue in healthy and ill persons and in which control was the dominant theme. Fatigue in healthy persons was also characterized with a sense of control over acute fatigue, while lack of control over chronic fatigue characterized fatigue in ill persons. The authors argued that a sense of lack of control may switch the perception of fatigue from acute to chronic and change one's self-image from healthy to ill, resulting in visits to healthcare providers in which fatigue is a prevalent complaint (5).

\section{MEASURES OF FATIGUE}

As fatigue is subjective by nature, the individual's perception of fatigue has become the focus of fatigue measurement (30). These self-report measures have different structures, such as simple global questions on fatigue (35), more complex unidimensional measures on fatigue in relation to daily activities (36) and more complex multidimensional measures of fatigue, including multiple dimensions (e.g., severity, impact) and/or manifestations (physical, cognitive emotional, behavioral) (37). Several validated tools have been developed to measure fatigue, but most of them were developed for screening and assessing clinical outcomes in different patient groups, e.g., patients with cancer, chronic fatigue syndrome, multiple sclerosis, stroke, or brain injury (see 38, 39). In the present overview, a few important measures of fatigue in the older population are described.

\section{Avlund Mob-T Scale and Lower-Limb-T Scale}

The Avlund Fatigue Scales were originally developed in order to measure more variations in functional ability among relatively well-functioning older people (40). As the results of a pilot study were that a majority of participants felt fatigued in their daily activities, fatigue was included as a category in the measurement of mobility and ADL (41). The scales are based on questions about six mobility items and five items on physical activities of daily living (PADL) (Table 3). Every activity is described relative to whether the respondents did or did not feel fatigued afterwards. The Mob-T Scale (Mobility-Tiredness) (6 items) and the Lower Limb-T Scale (Lower Limb-Tiredness) (5 
Table 3 - Avlund Mob-T Scale and Lower Limb-T Scale (36, 43).

\begin{tabular}{l} 
Fatigue \\
\hline Mob-T Scale (Mobility-Tiredness) \\
Transferring \\
Getting outdoors \\
Walking indoors \\
Walking outdoors in nice weather \\
Walking outdoors in poor weather \\
Walking on stairs to the second floor \\
Lower Limb-T Scale (Lower Limb-Tiredness) \\
Using toilet \\
Washing lower body \\
Dressing lower body \\
Putting on/taking off shoes/ stockings \\
Cutting toenails
\end{tabular}

items) count the number of activities managed without fatigue. The highest scale value thus describes no fatigue.

An analysis of the content validity of the scales in the 70- and 75-year survey of the Glostrup population (36, 40) and the baseline NORA-study (42) showed that all the questions about mobility and PADL in relation to fatigue were relevant and well-known to nearly all participants. The construct validity of the scales was tested by the Rasch model for item analysis, which showed that the items in both scales had satisfactory homogeneity $(36,43$, 44). The data have recently been re-analyzed with a new test based on the Rasch model, on the assumption of equal item discrimination - with satisfactory results (45). Reliability tests showed agreement from $94.3 \%$ to $98.3 \%$ and kappa values from 0.72 to 0.88 for the included items on intra-rater and inter-rater tests (46). A study of the discriminatory power of the scales among older adults in three service settings (47) showed that the whole range of the Mob-T Scale could be used in three very different populations: residents in elderly-friendly flats, users of home care, and non-users of home care. This means that the Mob-T Scale can reveal variations among people with both good and poor function. In addition, fatigue as measured by the scales is strongly associated with isometric muscle strength and simple function tests (48). The answers to the questions in the Mob-T and Lower-Limb T Scales are based on participants' own experiences, thus focus on fatigue in performing certain activities, and are therefore likely to reflect the physiologic and biologic consequences of doing these activities.

\section{Multidimensional Fatigue Inventory (MFI-20)}

The Multidimensional Fatigue Inventory (MFI-20) is a 20item self-report instrument, which covers the comprehensive nature of fatigue, dividing fatigue into the following dimensions: general fatigue, physical fatigue, mental fatigue, reduced motivation, and reduced activity (37) (Table 4). It has been validated in both healthy and ill populations. The authors found the instrument to have good internal consistency, construct validity and convergent validity (37, 49) in both Dutch and English. The MFI has been tested on radiotherapy patients, patients with chronic fatigue syndrome, psychology students, medical students, soldiers, and junior physicians (37). A confirmatory factor analysis confirmed that the questions actually described five different dimensions. Also, a study of patients with chronic liver disease showed that the measure had high reliability, construct validity and discriminative validity (50).

\section{SF-36 Vitality Scale}

The Short-Form-36 Health Survey (SF-36) was designed as a generic indicator of health status, for use in population surveys and evaluative studies of health policy. It can also be used in conjunction with disease-specific measures as an outcome measure in clinical practice and research. The SF-36 is formed of eight separate scales, including the SF-36 Vitality Scale, based on four items on energy and fatigue (Table 5). The SF-36 Vitality Scale has been tested in several methodological studies and comprehensive studies have been undertaken on its validity and reliability $(35,51,52)$ in both general population samples and various patient groups. The scale also showed satisfactory differential item functioning (53). Of the eight SF-36 scales, the Vitality-Scale has the best discriminatory power (35).

\section{FATIGUE AS A PREDICTOR OF ACCELERATED AGING}

There has been increasing interest in finding early signs of the aging process, because it may be used in preventive interventions with the aim of slowing the speed of aging. These early signs may manifest themselves as biological and physiological markers, but it is also possible

Table 4 - Dimensions in Multidimensional Fatigue Inventory (MFI-20) (49, 50).

General fatigue, referring to subject's general functioning, with statements such as 'I feel tired'

Physical fatigue, bodily sensations directly referring to tiredness, e.g., 'Physically I only feel able to do a little'

Reduced activity, a potential consequence of subjective fatigue, e.g., 'I think I do very little in a day'

Reduced motivation, reflecting lack of will to start any activity, e.g., 'I dread having to do things'

Mental fatigue, referring to cognitive symptoms such as having difficulty in concentration, e.g., 'It takes a lot of effort to concentrate on things' 
Table 5 - Items in Short Form-36 Vitality Scale (51-53).

\begin{tabular}{lccccc}
\hline & All the time & $\begin{array}{c}\text { Most of } \\
\text { the time }\end{array}$ & $\begin{array}{c}\text { A good bit } \\
\text { of the time }\end{array}$ & $\begin{array}{c}\text { Some of } \\
\text { the time }\end{array}$ & $\begin{array}{c}\text { A little of } \\
\text { the time }\end{array}$ \\
\hline Feeling full of pep & 1 & 2 & 3 & 4 & 5 \\
None of \\
the time
\end{tabular}

that the experience of fatigue among older adults is such an early aging sign.

The first studies on this issue came from the Copenhagen Gerontology Research Group at the Department of Social Medicine, University of Copenhagen. Their studies showed that fatigue in daily activities measured by the Avlund Fatigue Scales is an early indicator of aging, as it is associated with several poor health outcomes. For example, this can be seen in the results from a populationbased study from Glostrup, Denmark and Jyväskylä, Finland, which showed that fatigue at age 75 was significantly associated with subsequent disability at 5-year follow-up (34). The association was not mediated by walking limitations. The results (Table 6) also showed not only that the odds ratios for fatigue on onset of disability decreased when adjusted for comorbidity, cognitive performance and depressive mood, but also that the estimates stayed significant, even in the final adjusted model.
Another example is a study based on 70-year-old nondisabled persons with 15-year follow-ups (Table 7). Fatigue was significantly related to onset of disability at 5-, 10-, and 15-year follow-up (only marginally significant at the 15-year follow-up) and to mortality at 5-, 10- and 15year follow-ups (54). Maximal aerobic power was also related to the same outcomes, but did not seriously attenuate the association between fatigue and outcomes. Figure 1 shows differences in mortality during the 21-year follow-up among fatigued and non-fatigued individuals at age 70 .

Other results from these studies were:

1) fatigue in daily activities at age 75 is independently related to onset of disability in mobility and daily activities at five-year follow-up (33), onset of functional limitations during the next 5 years (55), risk of hospitalization and of being users of home help five years later (56), and not using regular dental services (57);

Table 6 - Fatigue in daily activities at age 75, as predictor of onset of disability at 5-year follow-up. Results of logistic regression analysis $(n=419)(34)$.

\begin{tabular}{|c|c|c|c|c|c|c|c|}
\hline (y) & $\begin{array}{l}\text { Crude } \\
\text { OR(95\%CI) }\end{array}$ & $\begin{array}{l}\text { Model 1 } \\
\text { OR(95\%CI) }\end{array}$ & $\begin{array}{l}\text { Model } 2 \\
\text { OR(95\%CI) }\end{array}$ & $\begin{array}{l}\text { Model } 3 \\
\text { OR(95\%CI) }\end{array}$ & $\begin{array}{l}\text { Model } 4 \\
\text { OR(95\%CI) }\end{array}$ & $\begin{array}{l}\text { Model } 5 \\
\text { OR(95\%CI) }\end{array}$ & $\begin{array}{l}\text { Final model } \\
\text { OR(95\%CI) }\end{array}$ \\
\hline Fatigue vs no fatigue & $\begin{array}{l}3.61 \\
(1.76-7.42)\end{array}$ & $\begin{array}{l}3.43 \\
(1.67-7.09)\end{array}$ & $\begin{array}{l}2.92 \\
(1.41-6.09)\end{array}$ & $\begin{array}{l}3.31 \\
(1.57-6.94)\end{array}$ & $\begin{array}{l}2.98 \\
(1.42-6.25)\end{array}$ & $\begin{array}{l}2.53 \\
(1.19-5.36)\end{array}$ & $\begin{array}{l}2.25 \\
(1.05-4.85)\end{array}$ \\
\hline $\begin{array}{l}\text { Income } \\
\text { Poor vs higher }\end{array}$ & $\begin{array}{l}1.96 \\
(0.93-4.11)\end{array}$ & $\begin{array}{l}1.74 \\
(0.81-3.71)\end{array}$ & & & & - & - \\
\hline 1-4 diseases vs none & $\begin{array}{l}4.74 \\
(1.42-15.79)\end{array}$ & & $\begin{array}{l}3.66 \\
(1.08-12.47)\end{array}$ & & & $\begin{array}{l}3.09 \\
(0.90-10.68)\end{array}$ & $\begin{array}{l}2.90 \\
(0.84-10.07)\end{array}$ \\
\hline $\begin{array}{l}\text { Cognition } \\
\text { Poor vs high } \\
\text { Medium vs high }\end{array}$ & $\begin{array}{l}10.35 \\
(2.34-45.81) \\
5.73 \\
(1.29-25.51)\end{array}$ & & & $\begin{array}{l}9.11 \\
(2.04-40.73) \\
6.03 \\
(1.34-27.07)\end{array}$ & & $\begin{array}{l}- \\
- \\
-\end{array}$ & $\begin{array}{l}- \\
- \\
-\end{array}$ \\
\hline $\begin{array}{l}\text { Depressive mood } \\
\text { us not }\end{array}$ & $\begin{array}{l}3.61 \\
(1.76-7.41)\end{array}$ & & & & $\begin{array}{l}2.98 \\
(1.42-6.25)\end{array}$ & $\begin{array}{l}2.64 \\
(1.25-5.57)\end{array}$ & $\begin{array}{l}2.66 \\
(1.26-6.60)\end{array}$ \\
\hline $\begin{array}{l}\text { Walking speed } \\
\text { Slow vs quick } \\
\text { Medium vs quick }\end{array}$ & $\begin{array}{l}\mathbf{3 . 3 0} \\
\mathbf{( 1 . 0 8 - 1 0 . 0 7 )} \\
2.75 \\
(0.87-8.68)\end{array}$ & & & & & & $\begin{array}{l}2.06 \\
(0.64-6.60) \\
2.10 \\
(0.64-6.87)\end{array}$ \\
\hline
\end{tabular}

Significant associations marked in bold type; Model 1. Adjusted by income; Model 2. Adjusted by number of diseases; Model 3. Adjusted by cognitive performance Model 4. Adjusted by depressive mood; Model 5 . Adjusted by the covariates which attenuated association between fatigue and onset of disability more than $20 \%$. Final model. Further adjusted by walking speed. 
Table 7 - Odds ratios of fatigue at age 70 on onset of disability and mortality at 5-, 10- and 15-year follow-ups (54).

\begin{tabular}{|c|c|c|c|c|}
\hline \multirow{3}{*}{ 5-year follow-up } & \multicolumn{2}{|l|}{ Onset of disability } & \multicolumn{2}{|l|}{ Mortality } \\
\hline & $(n=564)$ & & $(n=705)$ & \\
\hline & Crude OR $(95 \%$ CI) & Adjusted OR $(95 \% \text { CI })^{2}$ & Crude OR $(95 \%$ CI) & Adjusted OR $(95 \% \text { CI })^{2}$ \\
\hline Fatigue & $10.16(5.39-19.12)$ & $9.09(4.71-17.54)$ & $2.29(1.51-3.49)$ & $1.83(1.17-2.85)$ \\
\hline $\begin{array}{l}\text { Maximal power } \\
\text { not performed } \\
\text { Lowest } \\
\text { Medium } \\
\text { Highest }\end{array}$ & $\begin{array}{l}\mathbf{1 2 . 3 0}(\mathbf{( 4 . 2 3 - 3 5 . 6 5 )} \\
\mathbf{5 . 3 5}(\mathbf{2 . 0 1 - 1 4 . 2 8 )} \\
2.75(0.99-7.61) \\
1.0\end{array}$ & $\begin{array}{l}\mathbf{6 . 4 2}(\mathbf{( 2 . 0 1 - 2 0 . 4 8 )} \\
2.66(0.89-8.02) \\
1.85(0.64-5.35) \\
1.0\end{array}$ & $\begin{array}{l}3.37(1.50-7.56) \\
2.29(1.14-4.60) \\
2.02(1.00-4.07) \\
1.0\end{array}$ & $\begin{array}{l}\mathbf{3 . 3 2}(\mathbf{( 1 . 4 0 - 7 . 8 4 )} \\
\mathbf{3 . 2 3}(\mathbf{1 . 4 6 - 7 . 1 4 )} \\
1.20(0.97-4.13) \\
1.0\end{array}$ \\
\hline 10-year follow-up & $(n=360)$ & & $(n=705)$ & \\
\hline Fatigue & $\begin{array}{l}\text { Crude OR }(95 \% \text { CI) } \\
\mathbf{2 . 2 8}(\mathbf{1 . 4 7 - 3 . 5 4 )}\end{array}$ & $\begin{array}{l}\text { Adjusted OR }(95 \% \text { CI })^{2} \\
\mathbf{1 . 8 7}(\mathbf{1 . 1 7 - 2 . 9 9 )}\end{array}$ & $\begin{array}{l}\text { Crude } O R(95 \% \text { CI) } \\
\mathbf{2 . 3 4}(\mathbf{1 . 7 1 - 3 . 2 1 )}\end{array}$ & $\begin{array}{l}\text { Adjusted OR }(95 \% \text { CI })^{2} \\
\mathbf{2 . 1 6}(\mathbf{1 . 5 2 - 3 . 0 5 )}\end{array}$ \\
\hline $\begin{array}{l}\text { Maximal power }{ }^{1} \\
\text { not performed } \\
\text { Lowest } \\
\text { Medium } \\
\text { Highest } \\
\end{array}$ & $\begin{array}{l}4.85(1.78-13.20) \\
5.29(2.45-11.40) \\
2.49(1.13-5.50) \\
1.0\end{array}$ & $\begin{array}{l}4.28(1.51-12.11) \\
4.54(1.84-11.16) \\
2.33(1.03-5.30) \\
1.0\end{array}$ & $\begin{array}{l}2.73(\mathbf{1 . 4 9 - 5 . 0 1 )} \\
1.17(0.72-1.89) \\
1.54(0.96-2.49) \\
1.0\end{array}$ & $\begin{array}{l}\mathbf{2 . 3 7} \mathbf{( 1 . 2 1 - 4 . 6 4 )} \\
1.37(0.76-2.47) \\
1.48(0.89-2.46) \\
1.0\end{array}$ \\
\hline 15-year follow-up & $(n=181)$ & & $(n=705)$ & $195 \times 1=0$ \\
\hline Fatigue & $\begin{array}{l}\text { Crude OR }(95 \% \text { CI) } \\
\mathbf{2 . 1 5} \text { (1.16-3.99) }\end{array}$ & $\begin{array}{l}\text { Adjusted OR }\left(95 \% \text { CI }{ }^{2}\right. \\
1.84(0.93-3.64)\end{array}$ & $\begin{array}{l}\text { Crude } O R(95 \% \text { CI) } \\
\mathbf{2 . 6 1}(\mathbf{1 . 9 1 - 3 . 5 8 )}\end{array}$ & $\begin{array}{l}\text { Adjusted OR }(95 \% \text { CI })^{2} \\
\mathbf{2 . 3 1}(\mathbf{1 . 6 4 - 3 . 2 4 )}\end{array}$ \\
\hline $\begin{array}{l}\text { Maximal power }{ }^{1} \\
\text { not performed } \\
\text { Lowest } \\
\text { Medium } \\
\text { Highest }\end{array}$ & $\begin{array}{l}3.06(0.84-11.18) \\
\mathbf{5 . 4 4}(\mathbf{2 . 1 6 - 1 3 . 7 4 )} \\
2.22(0.89-5.52) \\
1.0\end{array}$ & $\begin{array}{l}2.87(0.75-10.97) \\
\mathbf{4 . 4 3}(\mathbf{1 . 4 5 - 1 3 . 5 6 )} \\
2.06(0.79-6.44) \\
1.0\end{array}$ & $\begin{array}{l}\mathbf{2 . 8 9}(\mathbf{1 . 5 2 - 5 . 5 2 )} \\
\mathbf{1 . 6 0}(\mathbf{1 . 0 2 - 2 . 5 3 )} \\
1.48(0.94-2.35) \\
1.0\end{array}$ & $\begin{array}{l}2.98(\mathbf{1 . 4 4 - 6 . 1 5 )} \\
\mathbf{2 . 4 1}(\mathbf{1 . 3 4 - 4 . 3 5 )} \\
1.63(0.99-2.69) \\
1.0\end{array}$ \\
\hline
\end{tabular}

2) sustained fatigue from age 75 to age 80 is significantly related to functional decline and mortality from age 80 to 85 (58);

3) fatigue in daily activities in two age groups (75 and 80) is a strong independent determinant of onset of mobility disability at 11/2-year follow-up (59);

4) fatigue in mobility is related to physical functioning and use of services at one-year follow-up in an older population (age 70-85), but not in a young one (60);

5) fatigue measured by the SF-36-Vitality Scale is related to physical functioning and use of services at oneyear follow-up in both a young and an older population (60).

More recently, other research groups have studied the effects of fatigue in older populations. Two cross-sectional studies show that older persons who report fatigue have significantly less good physical performance $(61,62)$, slower walking speed, and more mobility- and IADL-disability (62). A few longitudinal studies show that participants with fatigue have more restricted activity at $1 \frac{1}{2}$ year follow-up (63), poorer physical function, ADL and slower gait speed at 3-year follow-up (64), increased healthcare utilization and mortality (15), and higher risk of mortality during 10-year follow-up (65).

Fatigue as a predictor of other outcomes

The results from the Copenhagen Gerontology Research Group also showed that fatigue has an effect on activities and social relations. Results from cross-sectional data from the 70-year study in Glostrup showed that men and women with a low score on the Mob-T Scale were more likely to be less active with regard to physical, intellectual, cultural and social activities, compared with persons with high scores on the scale (66). A study on 75and 80-year old persons in four counties in Denmark showed that older adults who developed fatigue or who continuously felt fatigued when performing their daily activities during $4 \frac{1}{2}$ years were more likely to show a concurrent decline in their physical activities during the same period (67). It was also shown that women who felt fatigued in their daily activities at age 75 had fewer social network activities compared with non-fatigued women, 
i.e., they had little sustained contact with children and little sustained diversity in social relations over the next 5 years (68).

To summarize, the Copenhagen Group has demonstrated the significance of fatigue in young-old and the oldold, among men and women, and among older adults in different populations, i.e., in Glostrup, in three other counties of Zealand (Denmark), Southern Jutland (Denmark), Aarhus and Jyväskylä (Finland).

Studies have also examined whether fatigue is predictive of adverse health outcomes in younger samples and in patient populations. Nilsson et al. (69) showed that fatigue in 40-year old women was a significant predictor of early menopause, which may be viewed as an indicator of premature aging. Schultz et al. (70) showed that low vitality among workers was predictive of not returning to work 4-6 weeks after low back injury. A study in a Dutch working population showed that high levels of fatigue during two successive periods of four months were related to onset of infections (common cold, flu-like illness, gastroenteritis) (71) and that fatigue severity was a strong predictor of development of chronic fatigue syndrome four years later (72). With a measure of fatigue which reflects feelings of exhaustion, several studies showed that fatigue in the general adult population is positively related to incident non-fatal heart disease $(73,74)$, fatal myocardial infarction (74) and stroke (75). A study in a Dutch general practice among adult patients over a period of 15 years showed that people who had presented fatigue as a reason for encounter and had been diagnosed with fatigue, after an average of 19 months, did considerably worse than controls, defined as general practice patients who did not present fatigue as a reason for en-



Fig. 1 - Survival curves among 70-year-olds with and without fatigue during 21-year follow-up. counter (76). The first group had fatigue which had lasted longer and resulted in more functional limitations, their overall health was worse, and they had higher depression and anxiety scores. Groenvold et al. (77) found that low levels of fatigue independently predicted longer recurrence-free and overall survival in newly diagnosed breast cancer patients, controlling for biological factors.

More research is needed to elucidate several research questions on fatigue as an early aging indicator, such as: How is fatigue related to biological and physiological indicators of aging? Are changes in fatigue associated with biological and physiological aging changes, or do they take place independently of each other? Is fatigue related to onset of disease? Is fatigue predictive of adverse outcomes also in individuals in midlife, in both men and women, and with the same strength?

\section{POSSIBLE EXPLANATIONS}

There are several explanations for the finding that fatigue in older adults is related to functional decline and other adverse health outcomes.

\section{The disease explanation}

The first explanation is that fatigue may be a consequence of disease. People get fatigued because they are ill and become disabled, use health services or die because of the disease. Several cross-sectional studies in the general population of older people have shown that comorbidity is related to fatigue (78-80), but that specific diseases are also associated with it. This is seen specifically for musculoskeletal diseases $(78,79,81)$, but also for neurological and cardiovascular diseases (78), bronchitis, glucose intolerance and arteriostenosis (81) and abdominal syndromes (upper dyspepsia and irritable bowel syndrome) (82). A few longitudinal studies also found that comorbidity (80) and some specific diseases were predictive of onset of fatigue, e.g., respiratory symptoms and urinary incontinence (15) and infections (common cold, flu-like illness, gastroenteritis) (71).

Nevertheless, when the association between fatigue and adverse outcomes was adjusted for diseases (comorbidity, specific diseases) the estimates were attenuated, but the strong association between fatigue and outcomes persisted $(33,34,54,58,64)$. In spite, the associations between fatigue and functional decline may still be due to other diseases, which were not adjusted for in any of the analyses and which may be related to fatigue, e.g., diagnosed depression or Alzheimer's disease, by special combinations of diseases or the combination of having one disease and other impairments.

\section{The physiological explanation}

Another explanation is that fatigue is a consequence of age-related physiological and biological changes which are not disease-based, and that fatigue may thus be an indi- 
cator of frailty. This explanation is based on the definition of fatigue as a biologic syndrome of decreased reserve capacities and decreased resistance to stressors, resulting from cumulative declines across multiple physiologic systems - declines that have not yet caused open disability. I propose that the organs/systems which play the largest role in these findings are three main organs/systems of great importance in the disablement process: muscle function, cardiovascular/pulmonary function, and cognitive function. There are strong age-related declines in these three organs/systems.

Changes in muscle function with old age include decreased number of motor units and loss of muscle strength, muscle mass, alpha motor neurons and muscle cells. There are also changes in muscle composition with increasing infiltration of fat and connective tissue (83). Muscle fatigue is a specific component of muscular performance, which is typically measured as a loss of force during repeated or continuous activation, also called muscular endurance. Alterations in muscle with advanced age which may contribute to a decrease in muscle endurance include reduced blood supply and capillary density, impairment of glucose transport, lower mitochondrial density, decreased activity of oxidative enzymes, and decreased rate of phosphocreatine repletion.

Age-related changes in muscle strength in older adults (84) are influenced by a similar decrease in muscle mass caused by loss of motor neurons, lower levels of steroid hormones, a reduced dietary protein, and decreased physical activity (85-87). Loss of muscle mass will theoretically affect oxygen demand and perfusion (oxygen delivery) during muscle contractions at the same relative force levels. In addition to muscle mass, maximal voluntary muscle strength is determined by neural drive from the motor cortex to muscles (88). Maximal voluntary muscle strength is thus an indicator of the functioning of both neural and muscular systems (84).

The overall rate of decline in muscle strength is about $8 \%$ per decade (83). Thus, during the course of daily living, older people may be relatively close to their maximal capacity. It is well-established that older adults are not able to perform daily activities when they fall below certain threshold levels of muscle strength $(89,90)$. Although old humans may not demonstrate increased fatigability compared with young subjects during performance of normalized tasks, they are required to use a greater percentage of their reduced maximal strength for activities of daily living (i.e., absolute tasks), so that their rate of recovery (amount and duration) may be impaired after such tasks (91). The successful repeatability of tasks that require a reasonable level of force or power output is fundamental for the aged population to maintain their independence. Bautmans et al. (92) found that muscle fatigue in healthy older adults was related to subjective fatigue. For example, increased muscle fatigue may limit the time that a person can stand or the number of stairs that a person can descend or ascend, leading to reduced performance in ADL and increased subjective fatigue.

Several studies have demonstrated age-related changes in cardiovascular (93) and pulmonary function (94). The biological age-related changes in the cardiovascular system are first of all manifested as a decrease in the heart minute volume (95). Age-related changes in the pulmonary system are caused by changes in the anatomical structures of that system (e.g., decreased elasticity of the lungs, reduction in lung volume, a decrease in rib elasticity), which cause deterioration in vital capacity and forced expiratory volume (96). These changes in lung function combined with reduced maximal heart volume result in decreased aerobic capacity (95).

Aerobic capacity is the rate of oxygen consumption during activity, and is determined predominantly by skeletal muscle function. With aging, the oxygen cost of activities becomes a greater percentage of an individual's maximum aerobic capacity $\left(\mathrm{VO}_{2} \mathrm{max}\right)$. For example, a sedentary 75-year-old healthy woman has a $\mathrm{VO}_{2}$ max of approximately $1.2 \mathrm{~L} / \mathrm{min}$, but the oxygen cost of climbing a flight of stairs is approximately $1.5 \mathrm{~L} / \mathrm{min}$. Both younger and older subjects self-pace activity to about $50 \%$ of their $\mathrm{VO}_{2} \max$. Therefore, reduced aerobic capacity should lead to reduced spontaneous activity with age or to more fatigue in performing daily activities (97).

Several studies have shown that general cardiac functioning (98) and reduced aerobic work capacity (54, 99, 100) are related to fatigue. It has been shown that older adults are not able to perform daily activities when they fall below certain threshold levels of aerobic capacity (89). With a measure of fatigue which reflects feelings of exhaustion, Appels et al. $(101,102)$ found that fatigue was positively related to angina pectoris and unstable angina pectoris at screening, as well as to future angina pectoris and non-fatal myocardial infarction. It is possible that general fatigue in daily activities is a better indicator of aging of the cardiovascular system (100), whereas fatigue as measured by Appels et al. $(101,102)$ may be a more precise early sign of cardiovascular disease.

\section{The cognitive decline explanation}

It is also well-documented that there is an aging-related loss in cognitive reserve capacities (103-106). The normal aging process includes changes in cognitive functions (intelligence, memory, learning, thinking), but many of these take place throughout life and are not necessarily linked to old age. This is the case of the so-called "fluid intelligence", which refers to speed, mental span, and reserve capacities in adaptation of information and responses to new and complex stimuli. These tasks are linked to neurobiologic factors and normally show a gradual decline during the last part of adulthood. Conversely, cognitive functions based on experience ("crys- 
tallized intelligence") may improve throughout life in favorable circumstances. These functions include knowledge, strategical insight, expertise, and everyday problem-solving $(107,108)$, and are considered to be more influenced by life history and social factors than by age (109). The declines with age are smaller for these tasks than for tasks related to neurobiologic factors $(103,104)$.

A previous study on the association between fatigue and cognitive function showed that participants with poor self-reported memory and decreased cognitive performance reported more fatigue when performing basic ADL (110) and more complex activities (IADL) (111). Many daily activities are characterized by relative complexity. Early signs of cognitive decline may complicate the ability to perform activities which used to be easy to perform. This is likely to lead to fatigue.

Considering the three systems taken together, whether the association between fatigue and adverse health outcomes is mediated by muscle strength has not been studied (62), and only one study adjusted for aerobic capacity (54), but this did not really attenuate the estimates. It is thus unknown whether the association between fatigue and disability is mediated by muscle strength, muscle power or muscle fatigue, or by other measures of pulmonary and cardiovascular function. Several studies on fatigue and onset of disability are adjusted by a combined measure of cognitive function $(33,34,64)$, but this did not attenuate the results. It is not known whether the estimates are influenced by specific measures of cognitive performance or by changes in cognitive function (both combined and individual measures) and whether these patterns vary according to age and gender. In addition, interactions between muscle function, cardiovascular function and cognition in relation to fatigue and adverse health outcomes are largely unknown.

\section{The biological explanation}

A biological explanation may also be given for the close associations between fatigue and acceleration of the aging process. There are three possible biological factors: mitochondria, telomeres, and low-grade inflammation, as they all are related to aging and all may be related to fatigue.

Mitochondria are the major source of energy production in the body and play a unique role in cellular homeostasis. Mitochondrial dysfunction can lead to reduced energy production, which may result in fatigue. In addition, decreased oxidative metabolism in mitochondria leads to increased anaerobic metabolism and production of lactic acid. Acidosis in skeletal muscle can be perceived as muscular fatigue. The mitochondrial theory of aging proposes that oxidants or free radicals produced in mitochondria lead to mitochondrial DNA damage, leading to mutations, defective encoded proteins, and impaired mitochondrial function (8). Damaged mitochondria are re- moved from otherwise healthy cells through autophagy; however, the efficiency of this process decreases with age.

The relationship between fatigue and DNA repair capacity, oxidative stress and mitochondrial dysfunction is not known.

Telomere loss is another biomarker of interest, because critically short telomeres trigger loss of cell viability in tissues, and this has been related to alterations in tissue function and loss of regenerative capabilities in aging. Hence, telomere length seems to be an important biomarker for aging.

Telomeres have been proposed as a universal biological clock which shortens in parallel with aging in cells (112). Telomeres are located at the end of the chromosomes, and consist of an evolutionarily conserved repetitive nucleotide sequence. Telomere length is highly variable among species, within species, within an organism, and even between chromosomes (112). Cumulative attrition takes place during aging, but with large variations. Telomere shortening is thus regarded as a biomarker of cellular senescence $(112,113)$. A very recent population-based study showed that telomere length is not related to survival or death from any underlying cause, but that it is positively related to having more years of healthy life. It is thus suggested that telomere length may be a biomarker of healthy aging (114).

Telomere length has been associated with several diseases, e.g., coronary heart disease, dementia and insulin resistance (115) which predispose to frailty. Woo et al. (115) also searched, in vain, for a possible correlation between frailty and telomere length. However, their study was based on a frailty index composed of a long list of different concepts, e.g., number of a variety of diseases, cognition, depression, muscle impairment, functional limitations, and disability. It did not analyse for the influence of these more specific aspects of the disablement process on telomere length. It is possible that the results were blurred by combining all kinds of information into one index. It is thus not yet known how specific measures of the disablement process and other aging signs such as fatigue are related to telomere length.

Low-grade inflammatory processes are increasingly regarded as a biological measure of frailty (116) and, as such, represent one point of entry to the multisystem dysregulation which characterizes aging. An evolving definition of inflammation in gerontology is low-grade activation of the innate immune system, leading to chronic production of inflammatory mediators. Inflammatory processes in general have been implicated as predictors of or contributors to chronic diseases and conditions of aging (117), such as cardiovascular disease (118), low cognitive performance (119), osteoarthritis and dementia (120), frailty $(121,122)$, muscle wasting (123), physical performance $(123,124)$, disability $(125,126)$ and mortality (127-129). These associations have been 
proposed to be caused by altered cytokine profiles, due to aging of the innate immune system and/or non-immune cell types, and/or age-related changes in body composition (117).

A few studies have shown that specific inflammatory markers are related to fatigue. Janszky et al. (130) found that high-sensitivity C-reactive protein (hsCRP) and Interleukin-6 (IL-6) are associated with fatigue in older women after recent myocardial infarction. Schubert et al. (131) found that IL-6, Interleukin-1 receptor antagonist (IL1ra) and neopterin are related to fatigue in cancer patients, and two studies showed that hsCRP is related to fatigue in population-based samples of 33-45-year-olds (132) and in persons over age 65 (62). However, Vestergaard et al. (62) also found that IL-6 and TNF-alpha are not related to fatigue in this older population. It is not known whether other inflammatory markers are related to fatigue in persons in midlife and old age, which inflammatory markers have the strongest associations, and whether inflammation mediates the association between fatigue and adverse health outcomes.

Future research will examine whether biological indicators such as telomere length, mitochondrial function and low-grade inflammation mediate the association between fatigue and adverse health outcomes.

\section{Psychosocial mechanisms}

Psychosocial factors may also play a role in the relationship between fatigue and accelerated aging, and include depression, socio-economic position and social relations.

\section{Depression}

Fatigue is one of the symptoms of depression, and the feeling of fatigue is thus included in several measures of depressive symptoms $(133,134)$. It is well-known that depression is related to changes in the central nervous system, but also that these associations are bidirectional. Depression may lead to changes in both central (cognition, behavior and affect) as well as peripheral functions (physiological, and immunologic responses), and vice versa, i.e., changes in cognition may cause depression. A hypothetical model of fatigue in aging proposes that psychosocial factors (e.g., stress and depression) plus individual differences (e.g., personality and neuroticism) can lead to fatigue directly or indirectly through inflammation. Both fatigue and inflammation interact with, and potentially modify, disease (8). It is thus very plausible that depressive symptoms explain some of the associations between fatigue and outcomes.

Several cross-sectional studies have shown associations between depression or depressive symptoms and fatigue $(17,135)$ and development of fatigue $(15,136$, 137). However, when adjusting the associations between fatigue and diverse outcomes by depressive symptoms, the results did not seriously change $(33,58,62,64)$. However, the possibility that associations are mediated by an actual measure of depression and that patterns of associations may vary by age and gender cannot be ruled out. In addition, the interactions between fatigue, depression and inflammation on adverse health outcomes are unknown.

\section{Importance of life-course factors}

Fatigue may also reflect the cumulative impact across multiple life domains, such as a cumulative negative impact of low social position and/or stressful social relations or lack of social relations throughout the life-span (138).

Population-based studies have shown that biological and social factors early in life are related to physical performance in midlife. For example, a direct relationship has been found between birth weight and hand grip strength in middle age $(139,140)$, between post-natal growth and childhood development of motor and cognitive abilities and midlife performance (141, 142), and between educational level of mothers and physical performance in midlife (143). However, studies on the influence of early life factors on fatigue in midlife or old age are very scarce. Harvey et al. (144) identified two early life factors - extreme childhood energy and BMI in the overweight range - which appeared to act as risk factors for fatigue at age 43 without comorbid psychiatric disorder.

As regards the influence of socio-economic position on fatigue, one study showed that education (135) is related to fatigue in old age, whereas Avlund et al. (145) showed that, among several indicators of socio-economic position, measures of material wealth were the strongest indicators of social position in relation to fatigue in old age. Material wealth may reflect the situation at a certain point in time, but it may also reflect the cumulative influence of education, occupation and material wealth throughout the life-course. People with poor material wealth in old age are likely to have been economically disadvantaged for most of their lives. Material wealth inequalities in fatigue in old age can thus be seen as the biological correlate of this process of differential accumulation of risk factors along the life-course. Osler et al. (146) showed that men with low childhood or adult social class had a higher risk of fatigue in midlife than men from the highest social classes.

Regarding social relations, it has been shown that lack of partnership is related to general fatigue (21) and that social disengagement was significantly associated with persistent fatigue and developing fatigue over a period of 18 months (15). In a qualitative study, Aaronson et al. (5) showed that most participants believed social support alleviates or prevents fatigue by providing instrumental aid and/or a listening ear. Others reported that their social supports often contributed to their fatigue. These findings are consistent with those of Dzurec (147), who reported that interpersonal relationships play a vital role in women's experience of fatigue and may in fact ex- 
acerbate it. No studies have analysed the influence of positive or strainful social relations during the life course on fatigue in midlife and old age.

Fatigue may also be seen as a kind of chronic reaction to the accumulated chronic strain of dealing with the effects of cumulated social stress throughout life, in addition to the physiological and biological decline which characterizes aging. However, it does not attenuate the associations between fatigue and functional decline to adjust by socio-economic factors $(33,34,58,59)$ and social relations $(33,58,59)$.

Two studies on the influence of factors in midlife on fatigue in old age showed strong and consistent associations between sustained smoking from age 50 to 70 and fatigue at age 75 (148), no relations between cumulated physical inactivity from age 50 to 70 and fatigue at age 75 (149), but strong associations between physical inactivity at age 70 and fatigue at age 75 (149).

No studies have analysed the influence of the development of biological, cognitive and social factors early in life on fatigue in old age. How early life circumstances influence fatigue in midlife and old age, how biological, cognitive and social factors early in life interact in relation to fatigue in midlife and old age, whether the influence of different early life factors vary in men and women, how negative influences during the life-course accumulate in relation to fatigue in midlife and old age, whether there are certain vulnerable periods when the effects of strain early in life have more effects on fatigue later in life, are still unknown factors.

\section{Additional explanations}

In the present overview, I propose that fatigue may capture initial dysregulation across a multiplicity of physiological and biological systems, first and foremost in the muscle, cardiovascular/pulmonary and cognitive systems, and that this dysregulation may be accelerated by psychosocial factors and by factors early in life. However, other types of age-related decline may also play a role, e.g., age-related decline in the nervous and sensory system (95), immunological system (150-152) and anemia (23). Additional explanations may include pain, sleep, medication and health behavior.

Sleep problems and fatigue often coexist as a consequence of sleep deprivation, and are often grouped together by patients who suffer from them, complaining of being tired. On closer examination, however, it can be seen that lack of sleep and fatigue are two distinct, albeit interrelated symptoms (7). Individuals with short sleep duration are significantly more fatigued than persons who sleep for longer periods (16) and older persons who report sleeping problems are more fatigued than others (80).

Pain is another specific symptom, which shares many common risk factors with fatigue (153). Pain has been shown to be among the strongest predictors of fatigue in patients with arthritis (154) and to be related to fatigue in population-based samples, cross-sectionally (80) and to development of fatigue (15).

Older people often take medications to help resolve acute or chronic ailments (155). Although these medications are intended to improve patients' health, they frequently have side-effects caused by excessive drug use, declining function in various physiological systems, and altered drug metabolism and excretion $(156,157)$. These are also likely to lead to fatigue.

It is also possible that lack of physical exercise mediates the associations. Several studies show that low physical activity is related to fatigue $(48,158)$ and to onset of fatigue $(18,22,136)$.

Some of the already described studies have actually adjusted the associations between fatigue and adverse outcomes by sleep (62), medications (59) and physical activity $(33,62)$, without attenuation of results. But much more research is needed about the interactions between these factors and fatigue on adverse health outcomes.

\section{FATIGUE - A SELF-REPORTED INDICATOR OF FRAILTY?}

According to the data presented, fatigue may be seen as a self-reported indicator of early frailty. The term frailty is often used interchangeably with disability and comorbidity to identify a physically vulnerable subset of older adults (159). However, there is growing consensus that frailty, disability and comorbidity are distinct clinical entities, causally related. Comorbidity is defined as the concurrent presence of two or more medically diagnosed diseases in the same individual; disability as difficulty or dependency in performing daily activities, and frailty as a physiologic state of increased vulnerability to stressors resulting from decreased reserves in multiple physiologic and biologic systems, and possible dysregulation of those systems (159). Thus, frailty is distinct from, but overlaps with, both comorbidity and disability. In addition, both frailty and comorbidity predict disability, adjusting for each other; disability may exacerbate frailty and comorbidity, and comorbid diseases may contribute to the development of frailty (159).

Like frailty, fatigue predicts disability, and I suggest that fatigue without disability represents an early stage of frailty before it has caused disability. As with true frailty, fatigue may be caused by increased vulnerability in multiple biologic and physiologic systems, and interactions between biologic and physiologic systems may add to the complexity. For instance, lower mitochondrial density or decreased activity of oxidative enzymes do not in themselves cause fatigue, but they may contribute to a decrease in muscle endurance, which leads to increased vulnerability. In addition, the state of fatigue may be accelerated because of the cumulative impact of social, mental and biological factors throughout the life-course, but this 
is likely to take place via biological and physiological pathways.

Frailty has been defined as a clinical syndrome, including unintentional weight loss, slow walking speed, weakness (hand grip strength), low physical activity and self-reported exhaustion (159-161). Some researchers have added even more variables to the definition of frailty, such as sensory impairments, poor social conditions, chronic diseases, and disability (e.g. 115). The resulting measure of frailty is thus often an indicator of an older person's overall health status (162).

Focusing on frailty may lead to too little focus on individual components of frailty (i.e., fatigue) which may in itself be an important predictor for adverse outcomes. At the same time, individuals with a disease that resembles the aspects of frailty may be erroneously considered to be frail. In the end, a single measurement such as fatigue may be an adequate, practical screen for vulnerability (162).

Recently Xue et al. (163) presented evidence for homogeneity in the initial manifestations of frailty, with fatigue or early development of weight loss significantly predicting more rapid onset of the frailty syndrome, whereas neither slow walking speed nor low activity at baseline was associated with incident frailty. Fatigue and/or weight loss were involved in $80 \%$ of transitions to frailty. This finding raises the possibility that decreased energy production or increased utilization is involved in the threshold transition in a final common pathway toward frailty. Plausibly fatigue and/or weight loss result from depletion of system redundancy or compensatory mechanisms, so that any new deficit leads to failure of the whole organism. Early detection of fatigue may imply early detection of subclinical changes or deficits at molecular, cellular and/or physiological level - and is thus a key in preventing or delaying the development of frailty. In the above study (163), it was shown that non-frail women with fatigue/exhaustion as initial presenting symptom were over three times more likely to become frail during a 7.5 year period compared with women without feelings of exhaustion/fatigue.

This indicates that, among an array of signs of frailty, fatigue is one of the most important indicators of a rapid decline in other such signs. Fatigue is related to all other components in the most general definitions of frailty, to weight loss (22), slow walking speed (34), hand grip strength (80) and low physical activity (48).

There is a need for more investigation of relationships between fatigue and frailty and between the subjective and objective components of frailty as defined by Fried et al. (159).

\section{CONCLUSION}

Fatigue is suggested to be not only a self-reported indicator of frailty, defined as a physiologic state of increased vulnerability to stressors resulting from decreased physiologic reserves and even dysregulation of multiple physiologic systems, but also that it may be accelerated because of the cumulative impact of social, mental and biological factors throughout the life-course. Fatigue in older adults is the result of multiple potentially modifiable factors, of which some may be fully treated or at least alleviated, thus slowing down the speed of the aging process.

\section{ACKNOWLEDGEMENTS}

This work was supported by the VELUX FOUNDATION and by a grant from the Nordea Foundation.

\section{REFERENCES}

1. David A, Pelosi A, McDonald E et al. Tired, weak, or in need of rest: fatigue among general practice attenders. BMJ 1990; 301: 1199-202.

2. Okkes IM, Oskam K. The probability of specific diagnoses for patients presenting with common symptoms. Fam Pract 2002; 51: 31-6.

3. Gialamas A, Beilby JJ, Pratt NL, Rhys H, Marley JE, Roddick JF. Investigating tiredness in Australian general practice. Do pathology tests help in diagnosis? Aust Fam Phys 2003; 32: 663-6.

4. Kenter EGH, Okkes IM, Oskam SK, Lamberts H. Tiredness in Dutch family practice. Data on patients complaining of and/or diagnosed with 'tiredness'. Fam Pract 2003; 20: 434-40.

5. Aaronson LS, Pallikkathayil L, Crighton F. A qualitative investigation of fatigue among healthy working adults. West $J$ Nurs Res 2003; 25: 419-33.

6. Chaudhuri A, Behan PO. Fatigue in neurological disorders. Lancet 2004; 363: 978-88.

7. Shen J, Barbera J, Shapiro CM. Distinguishing sleepiness and fatigue: focus on definition and measurement. Sleep Medicine 2006; 10: 63-76.

8. National Institute of Aging. Workshop on Unexplained Fatigue in the Elderly. Workshop Summary. National Institute of Aging, 2007.

9. Yu DSF, Lee DT, Man NW. Fatigue among older people: A review of the research literature. Int J Nurs Stud 2010; 47: 216-28.

10. Lewis $G$, Wessely $S$. The epidemiology of fatigue: more questions than answers. J Epidemiol Community Health 1992; 46: 92-7.

11. Santos-Eggimann B, Cuénoud P, Spagnoli J, Junod J. Prevalence of frailty in middle-aged and older community-dwelling Europeans living in 10 countries. J Gerontol Med Sci 2009; 64: 675-81.

12. Loge JH, Ekeberg $\varnothing$, Kaasa S. Fatigue in the general Norwegian population: Normative data and associations. J Psychosom Res 1998; 45: 53-65.

13. Tiesinga LJ, Dassen TWN, Halfens RJG, van den Heuvel WJA. Factors related to fatigue; priority of interventions to reduce or eliminate fatigue and the exploration of a multidisciplinary research model for further study of fatigue. Int J Nurs Stud 1999; 36: 265-80.

14. Lerdahl A, Wahl AK, Ruståen T, Hanestad BR, Moum T. Fatigue in the general population: A translation and test of the psychometric properties of the Norwegian version of the fatigue severity scale. Scand J Public Health 2005; 33: 123-30.

15. Cheng H, Gurland BJ, Maurer MS. Self-reported lack of energy (Anergia) among elders in a multiethnic community. J Gerontol Med Sci 2008; 63A: 707-14. 
16. Goldman SE, Ancoli-Israel S, Broudreau R et al. Sleep problems and associated day time fatigue in community-dwelling older individuals. J Gerontol Med Sci 2008; 63A: 1060-75.

17. Watt T, Groenvold M, Bjorner JB, Noerholm V, Rasmussen N-A, Bech P. Fatigue in the Danish general population. Influence of sociodemographic factors and disease. J Epidemiol Community Health 2000; 54: 827-33.

18. Chen MK. The epidemiology of self-perceived fatigue among adults. Prev Med 1986; 15: 74-81.

19. Ridsdale L, Evans A, Jerrett W, Mandalia S, Osler K, Vora H. Patients who consult with tiredness: frequency of consultation, perceived causes of tiredness and its association with psychological distress. Br J Gen Pract 1994; 44: 413-6.

20. van Mens-Verhulst J, Bensing J. Distinguishing between chronic and nonchronic fatigue, the role of gender and age. Soc Sci Med 1998; 47: 621-34.

21. Beutel ME, Weidner K, Schwarz R, Brähler E. Age-related complaints in women and their determinants based on a representative community study. Eur J Obst Gyn Reprod Biol 2004; 117: 204-12.

22. Martin P, Bishop A, Poon L, Johnson MA. Influence of personality and health behaviors on fatigue in late and very late life. J Gerontol Psych Sci 2006; 61B: P161-6.

23. Theou O, Jones GR, Overend TJ, Kloseck M, Vandervoort AA. An exploration of the association between frailty and muscle fatigue. Appl Physiol Nutr Metab 2008; 33: 651-65.

24. Nybo L, Secher NH. Cerebral perturbations provoked by prolonged exercise. Progr Neurobiol 2004; 72: 223-61.

25. Rubin E. Tiredness (In Danish). In: Salmonsen's Encyclopedia. Vol. XXIII. Copenhagen: Schultz, 1926: 860-1.

26. Thage O. Tiredness. In: The Danish National Encyclopedia. Vol. 19. Copenhagen: Gyldendal, 2001: 297-8.

27. Chaudhuri A, Behan PO. Fatigue and basal ganglia. J Neurol Sci 2000; 179: 34-42.

28. Tralongo P, Respini D, Ferraù F. Fatigue and aging. Crit Rev Onc Hematol 2003; 48A: S57-64.

29. Parse RR. The lived experience of feeling very tired: A study using the Parse Research Method. Nursing Science Quarterly 2003; 16: 319-25.

30. O'Conell C, Stokes EK. Fatigue. In Kauffman TL, Barr JO, Moran ML, eds. Geriatric Rehabilitation Manual, Second Ed. Churchill Livingstone Elsevier, 2007: 431-4.

31. Glaus A, Crow R, Hammond S. A qualitative study to explore the concept of fatigue/tiredness in cancer patients and in healthy individuals. Eur J Cancer Care 1996; 5: 8-23.

32. Ream E, Richardson A. Fatigue: a concept analysis. Int J Nurs Stud 1996; 33: 519-29.

33. Avlund K, Damsgaard MT, Sakari-Rantala R, Laukkanen P, Schroll M. Tiredness in daily activities among non-disabled old people as determinant of onset of disability. J Clin Epidemiol 2002; 55: 965-73.

34. Avlund K, Rantanen T, Schroll M. Tiredness and subsequent disability in older adults. The role of walking limitations. J Gerontol Med Sci 2006; 61A: 1201-5.

35. Bjorner JB, Damsgaard MT, Watt T, Groenvold M. Tests of data quality, scaling assumptions, and reliability of the Danish SF36. J Clin Epidemiol 1998; 51: 1001-11.

36. Avlund K, Kreiner S, Schultz Larsen K. Functional ability scales for the elderly. A validation study. Eur J Public Health 1996; 6: 35-42.

37. Smets EMA, Garssen B, Bonke B, de Haes JCJM. The
Multidimensional Fatigue Inventory (MFI) psychometric qualities of an instrument to assess fatigue. J Psychosom Res 1995; 39: 315-25.

38. Dittner AJ, Wessely SC, Brown RG. The assessment of fatigue. A practical guide for clinicians and researchers. J Psychosom Res 2004; 56: 157-70.

39. Hjollund $\mathrm{NH}$, Andersen $\mathrm{JH}$, Bech P. Assessment of fatigue in chronic disease: a bibliographic study of fatigue measurement scales. Health and Quality of Life Outcomes 2007; 5: 12 doi:10.1186/1477-7525-5-12.

40. Avlund K, Schultz Larsen K. What do 70 year old men and women actually do? And what are they able to do? From the Glostrup survey in 1984. Aging Clin Exp Res 1991; 3: 39-49.

41. Avlund K. Disability in old age. Longitudinal population-based studies of the disablement process. Dan Med Bull 2004; 51: 315-49.

42. Avlund K, Davidsen M, Schroll M, Gause Nilsson I, Laukkanen P, Heikkinen E. Self reported functional ability in three Nordic localities. A comparative study of Activities of Daily Living among 75 year old men and women in Glostrup, Gothenburg and Jyväskylä. Int J Health Sci 1994; 5: 119-28.

43. Avlund K, Kreiner S, Schultz Larsen K. Construct validation and the Rasch model: Functional ability of healthy elderly people. Scand J Soc Med 1993; 21: 233-46.

44. Avlund K, Era P, Davidsen M, Gause Nilsson I. Item bias in self reported functional ability among 75 year old men and women in three Nordic localities. Scand J Soc Med 1996; 24: 206-17.

45. Christensen KB, Kreiner S. Monte Carlo tests of the Rasch model based on scalability coefficients. $\mathrm{Br} J$ Math Stat Psychol 2010; 63: 101-11.

46. Avlund K, Thudium D, Davidsen M, Fuglsang Sørensen B. Are self ratings of functional ability reliable? Scand $\mathrm{J}$ Occup Ther 1995; 2: 10-6.

47. Avlund K, Holstein BE. Functional ability among elderly people in three service settings. The discriminatory power of a new functional ability scale. Eur J Epidemiol 1998; 14: 783-90.

48. Avlund K, Schroll M, Davidsen M, Løvborg B, Rantanen T. Maximal isometric muscle strength and functional ability in daily activities among 75 year old men and women. Scand J Med Sci Sports 1994; 4: 32-40.

49. Smets EMA, Garssen B, Cull A, de Haes JCJM. Application of the Muldimentional Fatigue Inventory (MFI-20) in cancer patients receiving radiotherapy. $\mathrm{Br} J$ Cancer 1996; 73: 241-5.

50. Ünal G, de Boer JB, Borsboom JJM, Bouwer JT, Essink-Bot M$\mathrm{L}$, de Man RA. A psychometric comparison of health-related quality of life measures in chronic liver disease. J Clin Epidemiol 2001; 54: 587-96.

51. McHorney CA, Ware JE, Raczek AB. The MOS 36-Item ShortForm Health Survey (SF-36): II. Psychometric and clinical tests of validity in measuring physical and mental health constructs. Med Care 1993; 31: 247-63.

52. McHorney CA, Ware JE, Lu JF, Sherbourne CD. The MOS 36Item Short-Form Health Survey (SF-36): III. Tests of data quality, scaling assumptions, and reliability across diverse patient groups. Med Care 1994; 32: 40-66.

53. Bjorner JB, Kreiner S, Ware J, Damsgaard MT, Watt T, Bech P. Differential item functioning in the Danish translation of the SF36. J Clin Epidemiol 1998; 51: 1189-202.

54. Schultz-Larsen K, Avlund K. Tiredness in daily activities: A subjective measure for the identification of frailty among non-disabled community-living older adults. Arch Gerontol Geriatr 2007; 44: 83-93.

55. Avlund K, Sakari-Rantala R, Rantanen T, Pedersen AN, Frändin 
$\mathrm{K}$, Schroll M. Tiredness and onset of walking limitations in older adults. Letter to the editor. J Am Geriatr Soc 2004; 52: 1963-5.

56. Avlund K, Damsgaard MT, Schroll M. Tiredness as determinant of subsequent use of health and social services among nondisabled elderly people. J Aging Health 2001; 13: 267-86.

57. Avlund K, Holm-Pedersen P, Schroll M. Functional ability and oral health among older people: A longitudinal study from age 75 to 80. J Am Geriatr Soc 2001; 49: 954-62.

58. Avlund K, Pedersen AN, Schroll M. Functional decline from age 80 to 85 . Influence of preceding changes in tiredness in daily activities. Psychosom Med 2003; 65: 771-7.

59. Avlund K, Vass M, Hendriksen C. Onset of mobility disability among community-dwelling old men and women. The role of tiredness in daily activities. Age Ageing 2003; 32: 579-84.

60. Avlund K, Mehlsen M, Thomsen DK, Viidik A, Zachariae R. Physical functioning and use of health services at one-year followup in a young and old sample. The influence of fatigue. Dan Med Bull 2008; 55: 147-51.

61. Fagerstrom C, Persson H, Holst G, Hallberg IR. Determinants of feeling hindered by health problems in daily living at 60 years and above. Scand J Caring Sci 2008; 22: 410-21.

62. Vestergaard S, Nayfield SG, Patel KV et al. Fatigue in a representative population of older persons and its association with functional impairment, functional limitation, and disability. J Gerontol Med Sci 2009; 64A: 76-82.

63. Gill TM, Desai MM, Gahbauer EA, Holford TR, Williams CS. Restricted activity among community-living older persons: Incidence, precipitants, and health care utilization. Ann Intern Med 2001; 135: 313-21.

64. Hardy SE, Studenski SA. Fatigue and function over 3 years among older adults. J Gerontol Med Sci 2008; 63A: 1389-92.

65. Hardy SE, Studenski SA. Fatigue predicts mortality in older adults. J Am Geriatr Soc 2008; 56: 1910-4.

66. Avlund K, Legarth KH. Leisure activities among 70 year old men and women. Scand J Occup Ther 1994; 1: 35-44.

67. Elkjaer E, Poulsen T, Avlund K. Stability and change in physical activity in old age: the role of changes in disability. Eur J Ageing 2006; 3: 89-97.

68. Avlund K, Due P, Holstein BE, Heikkinen R-L, Berg S. Changes in social relations in old age. Are they influenced by functional ability? Aging Clin Exp Res 2002; 14S: 56-64.

69. Nilsson P, Møller L, Koster A, Hollnagel H. Social and biological predictors of menopause: a model for premature aging. J Intern Med 1997; 242: 299-305.

70. Schultz IZ, Crook J, Berkowitz J, Milner R, Meloche GR. Predicting return to work after low back injury using the Psychosocial Risk for Occupational Disability Instrument: a validation study. J Occup Rehabil 2005; 5: 365-76.

71. Mohren DCL, Swaen GMH, Kant IJ, Borm PJA, Galama JMD. Associations between infections and fatigue in a Dutch working population: Results of the Maastricht Cohort Study on Fatigue at Work. Eur J Epidemiol 2001; 17: 1081-7.

72. Huibers MJH, Kant IJ, Knottnerus JA, Bleijenberg G, Swaen $\mathrm{GMH}$, Kasl SV. Development of the chronic fatigue syndrome in severely fatigued employees: predictors of outcome in the Maastricht Cohort Study. J Epidemiol Community Health 2004; 58: 877-82.

73. Prescott E, Holst C, Grønbæk M, Schnohr P, Jensen G, Barefoot J. Vital exhaustion as a risk factor for ischaemic heart disease and all-cause mortality in a community sample. A prospective study of 4084 men and 5479 women in the Copenhagen City Heart Study. Int J Epidemiol 2003; 32: 990-7.
74. Schuitemaker GE, Dinant BJ, van der Pol GA, Appels A. Assessment of vital exhaustion and identification of subjects at increased risk of myocardial infarction in general practice. Psychosomatics 2004; 45: 414-8.

75. Schuitemaker GE, Dinant BJ, van der Pol GA, Verhelst AF, Appels A. Vital exhaustion as a risk indicator for first stroke. Psychosomatics 2004; 45: 114-8.

76. Kenter EGH, Okkes IM, Oskam SK, Lamberts H. Once tired, always tired? Limitations in function over time of tired patients in Dutch general practice. Eur J Gen Pract 2007; 13: 67-74.

77. Groenvold M, Petersen MA, Idler E, Bjorner JB, Fayers PM, Mouridsen HT. Psychological distress and fatigue predicted recurrence and survival in primary breast cancer patients. Breast Cancer Res Treat 2007; 105: 209-19.

78. Schroll M, Avlund K, Era P, Gause-Nilsson I, Davidsen M. Chronic diseases and functional ability in three Nordic localities (NORA 75). Facts, Research and Intervention in Geriatrics 1997; Suppl: 149-68.

79. Avlund K, Osler M, Damsgaard MT, Christensen U, Schroll M. The relations between musculoskeletal diseases and mobility among old people: Are they influenced by socio-economic, psychosocial and behavioral factors? Int J Behav Med 2000; 7 : 322-39.

80. Avlund K, Rantanen T, Schroll M. Factors underlying tiredness in older adults. Aging Clin Exp Res 2007; 19: 16-25.

81. Schultz Larsen K, Avlund K, Kreiner S. Functional ability of community dwelling elderly. Criterion-related validity of a new measure of functional ability. J Clin Epidemiol 1992; 45: 1315-26.

82. Kay L, Avlund K. Abdominal syndromes and functional ability in the elderly. Aging Clin Exp Res 1994; 6: 420-6.

83. Dos Santos MHH, Frontera WR, Larson L Skeletal muscle function in older people. In Kauffman TL, Barr JO, Moran ML, eds. Geriatric Rehabilitation Manual, Second Ed. Churchill Livingstone Elsevier, 2007: 9-16.

84. Rantanen T. Muscle strength, disability and mortality. Scand J Med Sci Sports 2003; 13: 3-8

85. Jubrias SA, Odderson IR, Esselman PC, Conley KE. Decline in isokinetic force with age: muscle cross-sectional area and specific force. Eur J Physiol 1997; 434: 246-53.

86. Luff AR. Age-associated changes in the innervation of muscle fibers and changes in the mechanical properties of motor units. Ann NY Acad Sci 1998; 854: 92-101.

87. Short KR, Nair KS. Mechanisms of sarcopenia of aging. J Endocrinol Invest 1999; 22: 95-105.

88. Galea V. Changes in motor unit estimates with aging. J Clin Neurophysiol 1996; 13: 253-60.

89. Schroll M, Schroll K, Osler M, Avlund K, Davidsen M. What can we learn from the EURONUT-SENECA study? Functionally capable for what? In Dall JLC, Ermini M, Herrling PL, MeierRuge W, Stähelin HB, Staufenbiel M, Eds. Adaptations in Aging. The 1994 Sandoz Lectures in Gerontology. London: Academic Press, Harcourt Brace \& Company, Publishers, 1995: 241-53.

90. Rantanen T, Guralnik JM, Izmirlian G et al. Association of muscle strength with maximum walking speed in disabled older women. Am J Phys Med Rehabil 1998; 77: 299-305.

91. Allman BL, Rice CL. Neuromuscular fatigue and aging: Central and peripheral factors. Muscle Nerve 2002; 25: 785-96.

92. Bautmans I, Gorus E, Njemini R, Mets T. Handgrip performance in relation to self-perceived fatigue, physical functioning and circulating IL-6 in elderly persons without inflammation. BMC Geriatr 2007; 7: 5. 
93. Era P, Schroll M, Hagerup L, Schultz-Larsen Jürgensen K. Changes in bicycle ergometer test performance and survival in men and women from 50 to 60 and from 70 to 80 years of age: Two longitudinal studies in the Glostrup (Denmark) population. Gerontology 2001; 47: 136-44.

94. Schultz-Larsen K. Chronic disease and functional ability among 70-year-old men and women (In Danish). Ph.D.Thesis. Copenhagen: Institute of Social Medicine, 1993.

95. Viidik A. The book about the aging body (In Swedish). Stockholm: Liber, 2002.

96. Cohen M. Pulmonary Considerations in the Older Patient. In Kauffman TL, Barr JO, Moran ML, eds. Geriatric Rehabilitation Manual, Second Ed. Churchill Livingstone Elsevier, 2007: 37-42.

97. Cohen M. Cardiac Considerations in the Older Patient. In Kauffman TL, Barr JO, Moran ML, eds. Geriatric Rehabilitation Manual, Second Ed. Churchill Livingstone Elsevier, 2007: 31-6.

98. Neleson R, Dar Y, Thomas K, Dimsdale JE. The relationship between fatigue and cardiac functioning. Arch Intern Med 2008; 168: 943-9.

99. Riley MS, O'Brien C, McCluskey DR, Bell NP, Nicholls DP. Aerobic work capacity in patients with chronic fatigue syndrome. BMJ 1990; 301: 953-6.

100. Schroll M, Løuborg B, Munck M, Avlund K, Davidsen M. Cardiac impairment as assessed by echocardiography related to work capacity and mobility in 75 year old Danes as part of NORA 75 Nordic Research on Ageing. Facts, Research and Intervention in Geriatrics 1997; Cardiology: 182-93.

101. Appels A, Mulder P. Fatigue and heart disease. The association between 'vital exhaustion' and past, present and future coronary heart disease. J Psychosom Res 1989; 33: 727-38.

102. Appels A. Why do imminent victims of a cardiac event feel so tired? Int J Clin Pract 1997; 51: 447-50.

103. Mortensen EL, Kleven M. A WAIS longitudinal study of cognitive development during the life span from ages 50 to 70 . Dev Neuropsychol 1993; 9: 115-30.

104. Mortensen EL, Høgh P. A gender difference in the association between APOE genotype and age-related cognitive decline. Neurology 2001; 57: 89-95.

105. Suutama T, Ruoppila I, Berg S. Changes in cognitive functioning from 75 to 80 years of age: A 5-year follow-up in two Nordic localities. Aging Clin Exp Res 2002; 14S: 29-36.

106. Wahl H-W, Kruse A. Psychological gerontology in Germany: recent findings and social implications. Aging Soc 2003; 23: 13163.

107. Fromholt P, Kirk H, Rørbye B, Schroll M, Viidik. Aging (In Danish). In: The Danish National Encyclopedia, Vol. 1. Copenhagen: Gyldendal, 1994: 227-32.

108. Steen G, Fromholt P, Äystö S, Berg S. Cognitive functioning in 75-year-olds: A study in three Nordic localities. Facts, Research and Intervention in Geriatrics 1997; Suppl: 79-92.

109. Smith J, Baltes PB. Trends and profiles of psychological functioning in very old age. In Baltes PB, Mayer KU, Eds. The Berlin Aging Study. Aging from 70 to 100 . Cambridge: Cambridge University Press, 1999: 197-226.

110. Avlund K, Fromholt P, Berg S, Davidsen M. Cognitive function and functional ability in daily life. Facts, Research and Intervention in Geriatrics 1997; Suppl: 93-105.

111. Avlund K, Fromholt P. Instrumental Activities of Daily Living: The Relationships to self-rated memory and cognitive performance among 75-year-old men and women. Scand J Occup Ther 1998; 5: 93-100.
112. Oeseburg H, de Boer UA, van Gilst WH, van der Harst P. Telomere biology in healthy aging and disease. Eur J Physiol 2009; E-pub ahead of print.

113. Starr J, Shiels PG, Harris SE et al. Oxidative stress, telomere length and biomarkers of physical aging in a cohort aged 79 years from the 1932 Scottish Mental Survey. Mech Ageing Dev 2008; 129: 745-51.

114. Njajou OT, Hsueh WC, Blackburn EH et al. Association between telomere length, specific causes of death, and years of healthy life in health, aging, and body composition, a populationbased cohort study. J Gerontol Med Sci 2009; 64: 860-4.

115. Woo J, Tang NLS, Suen E, Leung JCS, Leung PC. Telomeres and frailty. Mech Aging Dev 2008; 129: 642-48.

116. Walston J, Hadley EC, Ferrucci L et al. Research agenda for frailty in older adults: toward a better understanding of physiology and etiology: summary from the American Geriatrics Society/National Institute on Aging Research Conference on frailty in older adults. J Am Geriatr Soc 2006; 54: 991-1001.

117. National Institute of Aging. Workshop on Inflammation, Inflammatory Mediators, and Aging. Bethesda, Maryland. Workshop Summary. National Institute of Aging, 2005.

118. Bruunsgaard H, Christiansen L, Pedersen AN et al. The IL-6 $174 \mathrm{G}>\mathrm{C}$ polymorphism is associated with cardiovascular diseases and mortality in 80-year-old humans. Exp Gerontol 2004; 39: 255-61.

119. Krabbe KS, Mortensen EL, Avlund K et al. Genetic priming of a proinflammatory profile predicts low IQ in octogenarians. Neurobiol Aging 2009; 30: 769-81.

120. Bruunsgaard H, Benfield TL, Andersen-Ranberg K et al. The tumor necrosis factor alpha $-308 \mathrm{G}>\mathrm{A}$ polymorphism is associated with dementia in the oldest old. J Am Geriatr Soc 2004; 52: 1361-6.

121. Bruunsgaard H, Ladelund S, Pedersen AN et al. Predicting death from tumour necrosis factor-alpha and interleukin-6 in 80-year-old people. Clin Exp Immunol 2003; 132: 24-31.

122. Schmaltz HN, Fried LP, Zue Q-L et al. Chronic cytomegalovirus infection and inflammation are associated with prevalent frailty in community-dwelling older women. J Am Geriatr Soc 2005; 53 747-54.

123. Cesari M, Penninx BWJH, Pahor $M$ et al. Inflammatory markers and physical performance in older persons: The InCHIANTI Study. J Gerontol Med Sci 2004; 59A: 242-8.

124. McDermott MM, Ferrucci L, Liu K et al. D-Dimer and inflammatory markers as predictors of functional decline in men and women with and without peripheral arterial disease. J Am Geriatr Soc 2005; 53: 1688-96.

125. Ferrucci L, Harris TB, Guralnik JM et al. Serum IL-6 level and the development of disability in older persons. J Am Geriatr Soc 1999; 47: 639-46.

126. Penninx BWJH, Kritchevsky SB, Newman AB et al. Inflammatory markers and incident mobility limitation in the elderly. J Am Geriatr Soc 2004; 52: 1105-13

127. Roubenoff R, Parise H, Payette HA et al. Cytokines, insulin-like growth factor 1 , sarcopenia, and mortality in very old communitydwelling men and women: The Framingham Heart Study. Am J Med 2003; 115: 429-35.

128. Cesari M, Onder G, Zamboni V et al. C-Reactive Protein and lipid parameters in older persons aged 80 years and older. J Nutr Health Aging 2009; 13: 587-93.

129. Krabbe KS, Mortensen EL, Avlund K et al. Brain-derived neutrophic factor predicts mortality risk in older women. J Am Geriatr Soc 2009; 57: 1447-52. 
130. Janszky I, Lekander M, Blom M, Georgiades A, Ahnve S. Self-rated health and vital exhaustion, but not depression, is related to inflammation in women with coronary heart disease. Brain Behav Immun 2005; 19: 555-63.

131. Schubert C, Hong S, Natarajan L, Mills PJ, Dimsdale JE. The association between fatigue and inflammatory marker levels in cancer patients: A quantitative review. Brain Behav Immun 2007; 21: 413-27.

132. Cho HJ, Seeman TE, Bower JE, Kiefe CI, Irwin MR. Prospective association between $\mathrm{C}$-Reactive Protein and fatigue in the Coronary Artery Risk Development in Young adults Study. Biol Psychiatry 2009; 66: 871-8.

133. Radloff LS. The CES-D Scale: A self-report depression scale for research in the general population. Applied Psychological Measurement 1977; 1: 358-401.

134. Olsen LR, Jensen DV, Noerholm V et al. The internal and external validity of the Major Depression Inventory in measuring severity of depression. Psychol Med 2003; 33: 351-6

135. Murrell SA, Salsman NL, Meeks S. Educational attainment, positive psychological mediators, and resources for health and vitality in older adults. J Aging Health 2003; 15: 591-615.

136. Schroll M, Avlund K, Davidsen M. Predictors of five-year functional ability in a longitudinal survey of men and women aged 75 to 80. The 1914-population in Glostrup. Aging Clin Exp Res 1997; 9: 143-52.

137. Skapinakis $P$, Mavreas V. Cross-cultural differences in the epidemiology of unexplained fatigue syndromes in primary care. $\mathrm{Br}$ J Psychiatry 2003; 182: 205-9.

138. Seeman TE, Singer BH, Ryff CD, Love GD, Levy-Storms L. Social relationships, gender, and allostatic load across two age cohorts. Psychosom Med 2002; 64: 395-406.

139. Kuh D, Bassey J, Hardy R, Sayer AA, Wadsworth M, Cooper C. Birth weight, childhood size, and muscle strength in adult life: evidence from a birth cohort study. Am J Epidemiol 2002; 156: 627-33.

140. Sayer AA, Syddall HE, Gilbody HJ, Dennison EM, Cooper C. Does sarcopenia originate in early life? Findings from the Hertfordshire cohort study. J Gerontol Med Sci 2004: 59. M930-4.

141. Kuh D, Hardy R, Butterworth S et al. Developmental origins of midlife grip strength: findings from a birth cohort study. J Gerontol Med Sci 2006; 61: 702-6.

142. Kuh D, Hardy R, Butterworth S et al. Developmental origins of midlife physical performance: evidence from a British birth cohort. Am J Epidemiol 2006; 164: 110-21.

143. Guralnik JM, Butterworth S, Wadsworth ME, Kuh D. Childhood socioeconomic status predicts physical functioning a half century later. J Gerontol Med Sci 2006; 61: 694-701.

144. Harvey SB, Wessely S, Kuh D, Hotopf M. The relationship between fatigue and psychiatric disorders: Evidence for the concept of neurasthenia. J Psychosom Res 2009; 66: 445-54.

145. Avlund K, Holstein BE, Osler M, Damsgaard MT, Holm-Pedersen $\mathrm{P}$, Rasmussen NK. Social position and health in old age. The relevance of different indicators of social position. Scand J Public Health 2003; 31: 126-36.

146. Osler M, Madsen M, Andersen AMN et al. Do childhood and adult socioeconomic circumstances influence health and physical function in middle-age? Soc Sci Med 2009; 68: 1425-31.

147. Dzurec L. Relationship as an inherent component in healthy women's fatigue. West J Nurs Res 2002; 24: 441-53.

148. Støuring N, Avlund K, Schultz-Larsen K, Schroll M. The cumulative effect of smoking at age 50,60, and 70 on functional ability at age 75. Scand J Public Health 2004; 32: 296-302.

149. Christensen U, Støuring N, Schultz-Larsen K, Schroll M, Avlund K. Functional ability at age 77; is there an impact on physical inactivity from middle age to early old age? Scand J Med Sci Sports 2006; 16: 245-51.

150. Bennet BK, Hickie IB, Vollmer-Conna US et al. The relationship between fatigue, psychological and immunological variables in acute infectious illness. Aust NZ J Psychiatry 1998; 32: 180-6.

151. Drent M, Wirnsberger RM, de Vries J, van Dieijen-Visser MP, Wouters EFM, Schols AMWJ. Association of fatigue with an acute phase response in sarcoidosis. Eur Respir J 1999; 13: 718-22.

152. Whiteside TL, Friberg D. Natural killer cells and natural killer cell activity in chronic fatigue syndrome. Am J Med 1998; 105: 27S-34S.

153. Barr JO. Evaluation of pain in older individuals. In Kauffman TL, Barr JO, Moran ML, eds. Geriatric Rehabilitation Manual, Second Ed. Churchill Livingstone Elsevier, 2007: 443-6.

154. Zautra AJ, Fasman R, Parish BP, Davis MC. Daily fatigue in women with osteoarthritis, rheumatoid arthritis, and fibromyalgia. Pain 2007; 128: 128-35.

155. Ciccone CD. Pharmacology considerations for the aging individual. In Kauffman TL, Barr JO, Moran ML, eds. Geriatric Rehabilitation Manual, Second Ed. Churchill Livingstone Elsevier, 2007: 63-8.

156. Vass M, Hendriksen C. Polypharmacy and older people - a GP perspective. Z Gerontol Geriatr 2005; 38: (Suppl 1): 14-7.

157. Vass M, Hendriksen C. Medication for older people - Aspects of rational therapy from the general practitioner's point of view. Z Gerontol Geriatr 2005; 38: 190-5.

158. Crombie IK, Irvine L, Williams B et al. Why older people do not participate in leisure time physical activity: a survey of activity levels, beliefs and deterrents. Age Ageing 2004; 33: 287-92.

159. Fried LP, Ferrucci L, Darer J et al. Untangling the concepts of disability, frailty, and comorbidity: Implications for improved targeting and care. J Gerontol Med Sci 2004; 59: 255-63.

160. Bandeen-Roche K, Xue QL, Ferrucci L et al. Phenotype of frailty: characterization in the women's health and aging studies. J Gerontol Med Sci 2006; 61: 262-6.

161. Walston J, McBurnie MA, Newman A et al. Frailty and activation of the inflammation and coagulation systems with and without clinical comorbidities. Arch Intern Med 2002; 162: 2333-41.

162. Bergman H, Ferrucci L, Guralnik J et al. Frailty: An emerging research and clinical paradigm - issues and controversies. J Gerontol Med Sci 2007; 62A: 731-7.

163. Xue Q-L, Bandeen-Roche K, Varadhan R, Zhou J, Fried LP. Initial manifestations of frailty criteria and the development of frailty phenotype in the Women's Health and Aging Study II. J Gerontol Med Sci 2008; 63A: 984-90. 